\title{
A Neglected Unusual Galeazi Fracture Dislocation In 12 Years Child: Management
}

\author{
Uddin MN ${ }^{1}$, Islam MS ${ }^{2}$, Chowdhury $\mathrm{MR}^{3}$, Khan MAKA ${ }^{4}$, Hasan MR ${ }^{5}$, Hasan $\mathrm{MS}^{6}$
}

\begin{abstract}
A galeazi fracture is defined as a fracture of the shaft of the radius with dislocation of the distal radioulnar joint (DRUJ). Isolated radial shaft fractures with or without DRUJ dislocation in children are unusual in clinical practice. If there is fracture the degree of angulation is measured and accordingly managed. A 12 years boy came to the casualty department of Community Based Medical College Hospital Bangladesh $(\mathrm{CBMCH}, \mathrm{B})$ with the history of fall from bicycle on out stretcher right hand 5 years back, diagnosed to have fracture shaft of right radius. X-ray examination revealed old fracture at the junction of the middle and lower third of right radial shaft with feature of nonunion with volar angulation $30^{\circ}\left(180-150^{\circ}\right)$ and interosseous angulation $15^{\circ}\left(180-165^{\circ}\right)$. Patients was operated by open reduction and internal fixation (ORIF) of the fracture using dynamic compression plate (DCP) and screws and we corrected the angulation to near normal status and also correction of DRUJ done to its near normal anatomy. Postoperatively wound healed well and patient achieved full range of motion by three weeks. Radiologically the fixation was satisfactory and at the 6 weeks fracture was united. In conclusion, an old unusual galeazzi fracture dislocation in a child below 14 years with volar / dorsal / interosseus angulation more than $15^{\circ}$ and rotational angulation more than $30^{\circ}$ must be managed surgically to get near normal anatomy of bone as well as near normal range of motion.
\end{abstract}

Key words:

CBMJ 2015 January: Vol. 04 No. 01 P: 41-44

\section{Introduction}

Fracture of the forearm are common orthopaedic injuries in children ${ }^{1,2,3,4}$. Accounting for $30 \%$ to $50 \%$ of all pediatric fractures $5,6,7,8$. About $18 \%$ of all forearm fractures occur in the shaft of the radius and the ulna 9,10,11. In the forearm either both bones or one bone and one radioulnar joint (monteggia and galeazzi lesions) are typically injured and isolated fractures are relatively uncommon ${ }^{12}$. Therefore single bone fractures should always raise suspicion regarding additional injury to the proximal or distal radidunar joint $13,14,15$. A few papers state that isolated dislocation of the DRUJ and galeazzi fractures are unusual in children 16,17,18 and the diagnosis can therefore be over looked ${ }^{18,19}$. The galezzi fracture, which is named after the Italian surgeon Riccardo Galeazzi was first described by cooper in 1822. According to voigi and Lill ${ }^{20}$. the typical mechanism of injury is described as a fall on an out stretched hand in hyperpronation ${ }^{21}$. In children, this fracture occurs with an incidence of $0.3 \%$ to $2.8 \%$ of all forearm fractures 22,23 . The peak incidence occurs between the ages of 9 and 13 years ${ }^{23}$.

1 "Dr. Md. Nasir Uddin Associate Prof. \& Head Department of Orthopaedic CBMCB.

2. Dr. Md. Saiful Islam Assistant Professor, Department of Orthopaedic CBMCB.

3. Dr. Mamunur Rashid Chowdhury Assistant Professor Department of Orthopaedic CBMCB.

4. Dr. Md. Abul Kalam Azad Khan Assistant Professor Department of Anaesthesiology

5. Dr. Md. Rajibul Hasan Assistant Professor Department of Anaesthesiology CBMCB.

6. Dr. Md. Sabbir Hasan Ashik Registrar Department of Orthopaedic CBMCHB

"Address of correspondence Email :

Mobile: 01747761111 
In the pediatric population, good results after closed reduction and casting have been reported $^{13}$, The gold standard of conservative treatment in children is above elbow casting in supination $^{24}$. But our case was 5 years old maltreated case. So operative treatment is the only treatment option.

\section{Case Report}

A 12 years boy came to the casualty department of community Based Medical College Hospital Bangladesh as out door patient with the history of fall from bicycle 5 years back and there by fracture of right forearm bone. He was treated by kobiraj (Traditional healer) and child was reasonably well; but the mother of the child complain of painless swelling and deformity in lower $3^{\text {rd }}$ of right forearm for one year. On examination non tender subcutaneous bony swelling in the medial aspect at the junction of the middle and lower third of right forearm and pronation \& supination was restricted. X-ray of the right forearm revealed anteromedial angulated fracture of the shaft of the right radius, volar angulation was $23^{\circ}$ (Fig. I) and interoseous angulation $15^{\circ}$ (Fig II) and also revelead dislocation of DRUJ and also show features of non union. This was a old maltreated, neglected case and open reduction and internal fixation (ORIF) was the treatment of choice. The ends of the proximal \& distal fragment of the fractured radius are osteomized and a fragment of ulna also osteomized. ORIF by DCP \& Screws were done for fractured radius and ORIF by $1 / 3^{\text {rd }}$ tubular plate and screws were done for the iatrogenic fractured ulna. By these procedures we corrected the angulation and DURJ to near normal status (Fig. III). About $1.5 \mathrm{~cm}$ shortening of the forearm bones may be present but clinically no obvious shortening. Postoperatively wound healed well, excrcises started two days after surgery and patient achieved full range of motion by three weeks. Radiological fixation was satisfactory and at 6 weeks fracture was united.

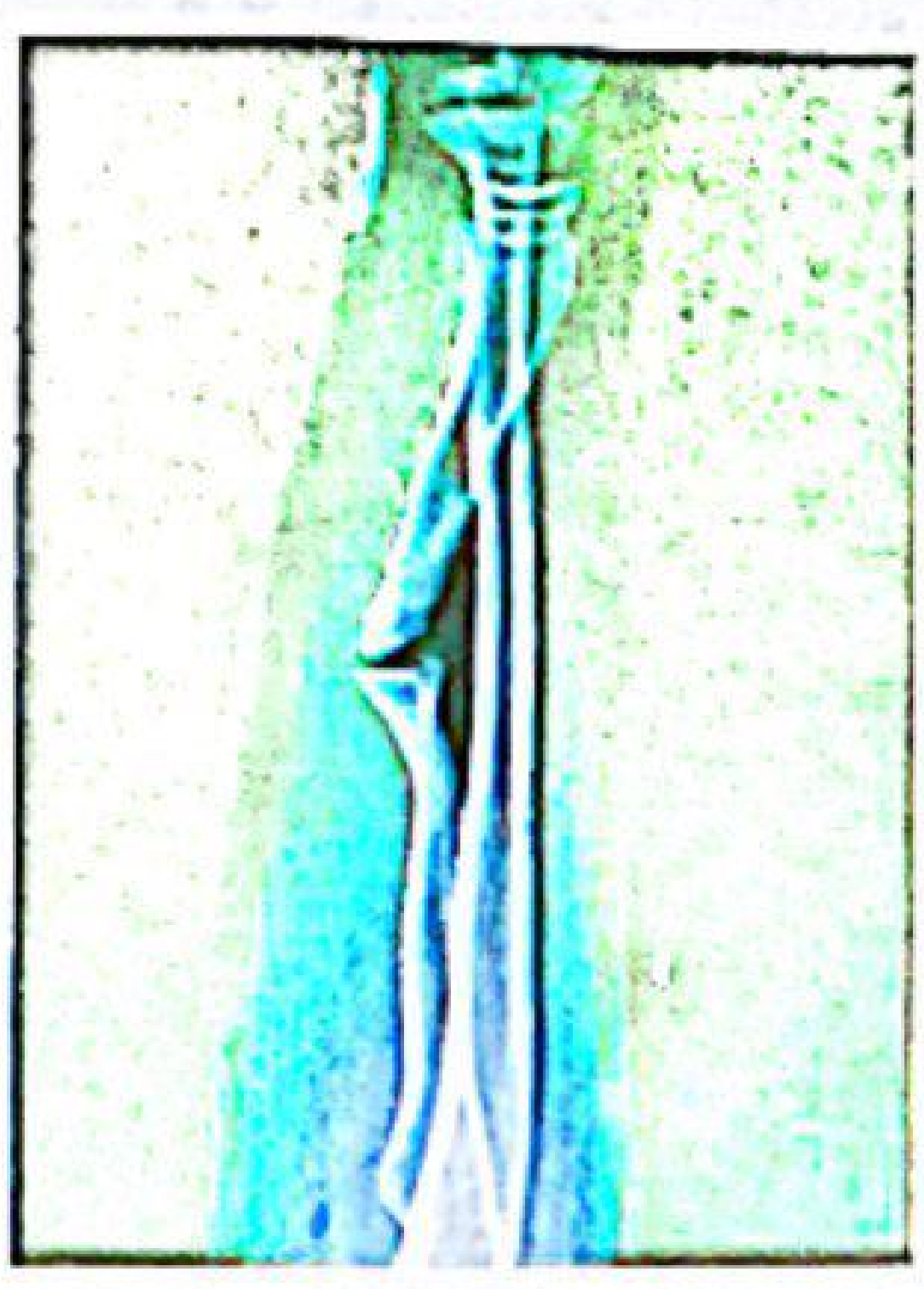

Figure-I

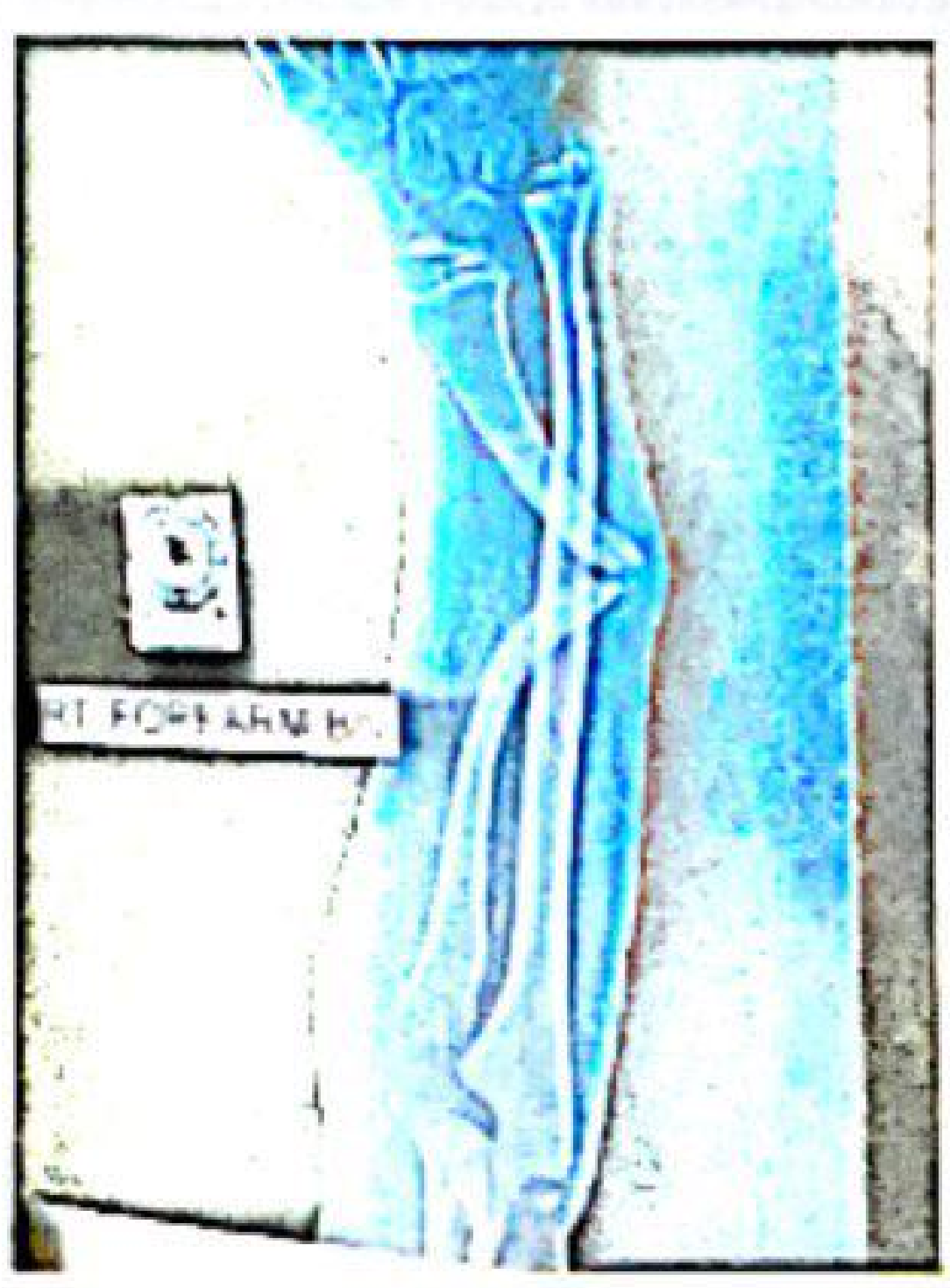

Figure-II

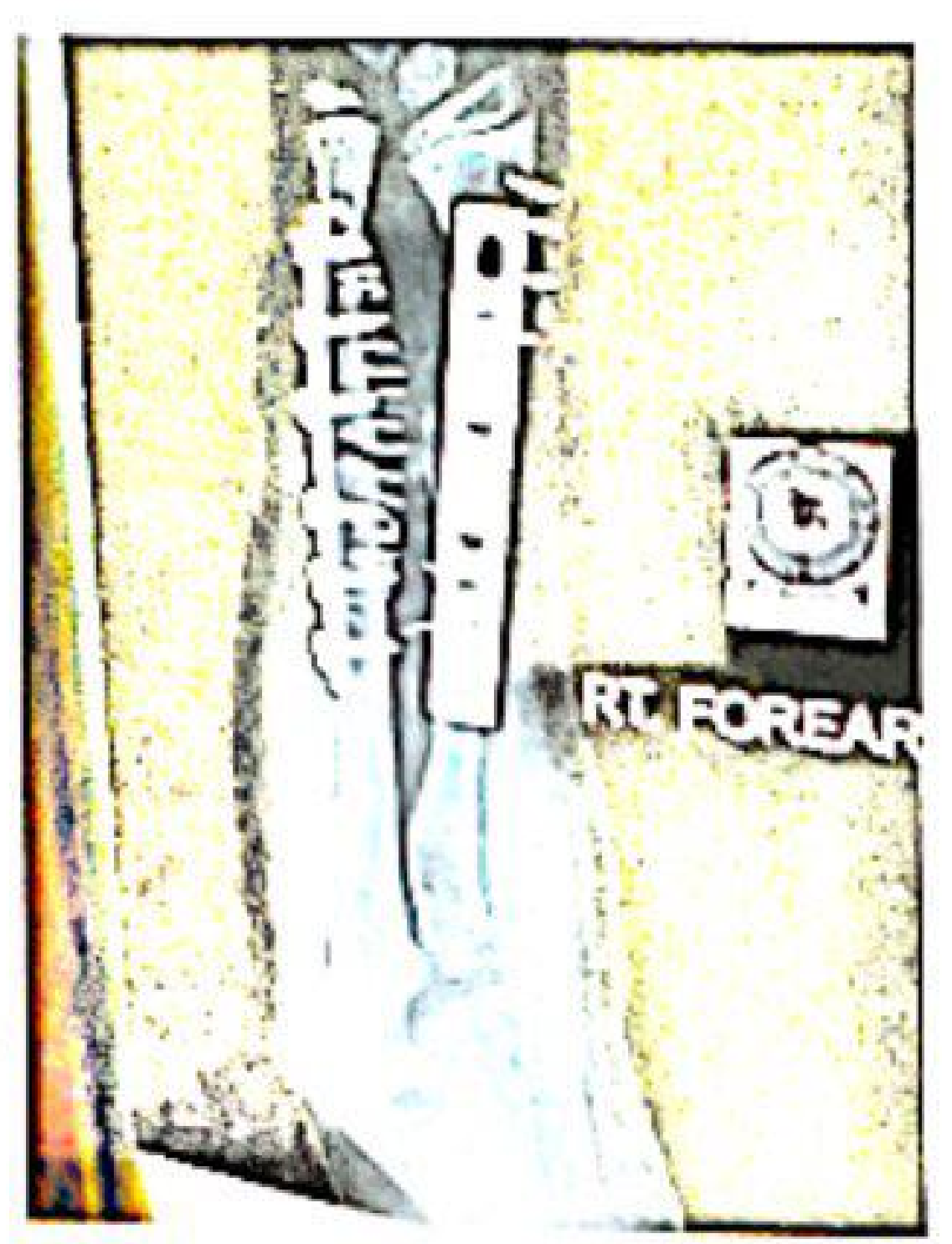

Figure-III

\section{Discussion}

Galeazzi fracture dislocation in children are unusual in clinical practice. Our case is a very rare as it was a five years old, maltreated neglected galeazzi fracture with nonunion. Deformity and agnulation is so much that fractured radius crors the ulna and palpable subcutaneously in the medial border of forearm. Fractured radius bowed medially concordant with walsh et at ${ }^{23}$ the median age 
of the patient was 11 years with the majority being male. In addition, it is accepted that the radius fracture accompanying the galeazzi lesion is located often at the junction of the middle and distal thirds of the bone $e^{25}$. Our patient was 12 years boy and fracture being located at the junction of middle and distal third of the right radius. In adult, galeazzi fracture usually require operative treatment. Numerous authors stated a considerable rate of secondary displacements and nonunion may results in case of conservative treatment ${ }^{13,26,27}$. In contrast to the adult population the treatment of galeazzi lesions in children usually has a good out come after conservative treatment with above elbow cast immobilization ${ }^{28}$. Incomplete fractures bowing fractures and intact periousteal structures provide residual stability after bone trauma in children. Our case is 5 years old, unusual, maltreated galeazzi fracture with fractured radius bowed medially and angulated about $45^{\circ}$ from the long axis of radius. So surgical treatment is the treatment of choice of this case.

Proximal and distal fragments of the radius which are bowed to the ulnar border of forearm are taken by osteotomy. A segment from the ulna was taken. This iatrogenic fractured ulna was fixed by $1 / 3^{\text {rd }}$ tubular plate \& screws. Segment of ulna was impregnated between proximal and distal fragments of radius. Radius was fixed by ORIF with DCP \& Screws.

\section{Conclusion}

Galeazzi fracture in children below 14 years with volar/ dorsal/ interoscous angulation of more than $15^{\circ}$ and rotational angulation of more than $30^{\circ}$ should be corrected surgically even in recent case to get the near anatomy of the bone \& normal range of motion. In an old case operation is mandatory. So our patient a 12 years old boy with 5 years old radial shaft fracture with features of non-union and associated with DRUJ dislocation was operated to correct angular deformities as well as correction of DRUJ to near normal anatomy which was very much justified.

\section{Reference}

1. Cheng JC, Shen WY. Limb Fracture pattern in different pediatric age groups : a study of 3,350 childeren. $J$ orthop Trauma. 1993; 7(1): 15-22. Doi : 10.10917/00005131-199302000-00004. [pubmed] [cross Ref.].

2. Landin LA. Fracture patterns in children Analysis of 8 , 682 fractures with special reference to incidence, etiology and secular changes in a Swedish urban population 1950-1979. Acta orthop scand suppi. 1983; 202:1-109. [pubmed].

3. Mann DC, Rajmaira S. Distribution of physeal and nonphyseal fracture in 2,650 long bone fractures in children aged 0-16 years. J pediatr Orthop. 1990; 10(6): 713-716. [pubmed].

4. Tredwell SJ, Peteghem K, Clough M. Pattern of forearm fractures in children. J. Pediatr Orthop. 1984; 4(5): 604608. [pubmed].

5. Bailey DA, Wedge JH, MC Cullocn RG, et al. Epidemiology of fractures of the distal end of the radius in children as associated with growth. J. Bone Joint surg Am. 1989; 71(8): 12-25-1231[pubmed].

6. Jones IE, Cannar $R$, Gouldign A. Distal Forearm fractures in New Zealand Children: annual rates in a geographically defined area. NZ Med J. 2000; 113(1120): 443-445. [pubmed].

7. Kramfolt $M$, Bodtker S. Epidemiology of distal forearm fractures in Danish children. Acta orthop scand. 1988; 59(5): 557-559. doi : 10.3109/1745367-8809148784. [pubmed] [Cross Ref.]

8. Worlock $P$, Stower $M$. Fracture patients in Nottingham children. I Pediatr Orthop. 1986;6(6): 656660[pubmed].

9. Armstrong PF, Joughlin VE, Clarke HM. Pediatric fractutes of the forearm, wrist and hand. In : Green NESME, Editor, Skeletal Trauma in Children. Philadephia : W.B. Sounders. Company : 1998. pp. 161-258.

10. Blount $W$, Shaefer $A$, Johnson J. Fracture of the forearm in children. JAMA. 1942; 120:111-116.

11. Gandhi RK, Wilson $P$, Mason Brown JJ, et al . Spontaneous correction of deformity following fracture of the forearm in children. Br J surg. 1962:30: 5-10. Doi: 10.1002/bjs 18005021903. [Pubmed] [Cross Ref].

12. Vainiorpaa S, Bostman $O$, Patiala $H$, et al. Internal fixation of forearm fractures in children. Acta Orthop scand. 1987: 58(2): 121-123.

13. Mikic ZD. Galeazzi fracture - dislocations. J Bone Joint surg Am. 1975; 57(8): 1071-1080. [pubmed].

14. Moore TM, Klein JP, Patzakis MJ, etal. Results of compression- plating of closed galeazzi fractures. J. Bone joint surg Am. 1985; 67(7) : 1015-1021.

15. Reckling FW. Unstable fracture dislocation of the forearm (Monteggia and Galeazzi lesions) J Bone joint surg. Am. 1982; 64(6): 857-863. 
16. Birch-Jenson A. Luxations of the distal radial ulnar joint. Acta chir scand. 1951; 101: 312-317.

17. Heiple $K$, Freehafer A. Van't Hof A. Isolated traumatic dislocation of the distal end of the ulna or distal radio ulnar joint. J Bone joint surg. AM. 1962; 44A: 13871393.

18. Walsh HP, MC Laren CA, Owen R. Galeazzi Fracture in children. J. Bone Joint surg. Br. 1987; 69(5): 730-733.

19. Rosa LAP, Ibarra SM. Incidencia de las fractures de Galeazzi en nioos. Acta ortop, Dica Mexicana 2002; 16 (6): 321-324.

20. Voigt $C$, Lill $H$. Combined fractures of the forearm: Monteggia, Galeazzi and Essex-Lopresti lesions. Aktuelle traumatol. 2004; 34: 270-277.

21. Reckling FW, Cordell LD. Unstable fracture dislocations of the forearm : the Monteggia and Galeazzi lesions. Arch Surg. 1968; 96:999-1007.

22. Schlickewei $W$, Obrerle $M$. (Forearm fractures in children) [ In German] Unfallchirurg. 2005; 108:223232.

23. Walsh HP, Mclaren CA, Owen R. Galeazzi Fracture in Children. J. Bone joint surg. Br. 1987; 69: 730-733.

24. Rodriguez- Merchan EC. Padiatric fractures of the forearm. Clin orthop Relat Res. 2005; 432:65-72.

25. Perron $A D$, Hersh RE, Brady WJ, Keats TGE. Orthopedic pitfalls in the ED: Galeazzi and Monteggia fracture dislocation. AM J Emerg. Med. 2001; 19:225228.

26. Hughston JC. Fracture of the distal radial shaft: mistakes in management. $J$ Bone joint Surg. AM. 1957:39; 249-264.

27. Reckling FW. Unstable fracture dislocations of the forearm (Monteggia and Galeazzi lesions) Bone joint surg. AM. 1982; 64 : 857-863.

28. Rothe $M$, Ruddy $T$. Stankovic $P$, sturmer KM. (Treatment of Galeazzi's fracture : is the surgical revision of the distal radioulnar joint necessary? (in German) Handchir Mikrochir plastchir, 2001; 33: 252257. 